EESTI NSV TEADUSTE AKADEEMIA TOIMETISED. 19. KOIDE KEEMIA * GEOLOOGIA. 1970, Nr. 4

ИЗВЕСТИЯ АКАДЕМИИ НАУК ЭСТОНСКОИ ССР. ТОМ 19 ХИМИЯ * ГЕОЛОГИя. 1970, № 4

И. КЛЕСМЕНТ, ВИЙВЕ ВАХЕССААР, О. ЭЙЗЕН

\title{
РАЗДЕЛЕНИЕ ИЗОМЕРНЫХ РЕЗОРЦИНОВ РАСПРЕДЕЛИТЕЛЬНОЙ ХРОМАТОГРАФИЕЙ
}

Подсмольная вода, образующаяся при полукоксовании горючего сланца, содержит некоторое количество низкомолекулярных двухатомных фенолов, которые выделяются экстракционным методом. В настоящєе время они широко применяются для синтеза разных клеевых смол и дубителей. Двухатомные фенолы в основном состоят из производных резорцина.

По данным газохроматографического анализа состав фенолов следующий: фенола - 5,6, крезолов - 4,6, резорцина - 2,6, 2-метилрезорцина $-1,5,5$-метилрезорцина $-35,0,4$-метилрезорцина $-13,0,5$-этилрезорцина - $13,7 \%$ и остальных неидентифицированных компонентов $24,0 \%$.

Количество отдельных компонентов в сыром продукте невелико. При применении подходящего метода разделения возможно производство из сырого продукта индивидуальных фенолов, в частности 5-метилрезорцина, который является основным компонентом смеси фенолов. Индивидуальные изомерные резорцины применяются в органическом синтезе для получения поликарбонатных смол и как реактивы в аналитической химии.

Разработано несколько методов для разделения сланцевых двухатомных фенолов на индивидуальные соединения. Один из методов - фракционная кристаллизация [ $\left.{ }^{1}\right]$. Некоторыми авторами $\left[{ }^{2}\right]$ использован для разделения метод зонной плавки. Зонная плавка, как и фракционная кристаллизация, основана на разных концентрациях компонентов систем в твердой и жидкой фазах.

Нами была сделана попытка разделить фенолы ректификацией. Для этого использовалась колонка с разделительной способностью в 40 теоретических тарелок при остаточном давлении 6-10 мм рт. ст. Состав полученных фракций определен газохроматографически, результаты представлены на рис. 1.

Выясняется, что из-за близких температур кипения отдельных компонентов достигнуто только небольшое обогащение 5-метилрезорцином. По данным литературы [3], резорцины разделяются при ректификацин лучше после перевода их в триметилсилиловые эфиры, но это связано с дополнительными довольно сложными операциями.

При разделении фенолов в тонком слое (частый случай распределительной хроматографии) [4] нами установлено, что алкилпроизводные резорцина разделяются в зависимости от степени экранирования гидроксильных групп алкильными радикалами. 5-Метилрезорцин и другие 
5-алкилпроизводные резорцина не имеют экранирующих групп, поэтому они адсорбируются сильнее, чем остальные производные резорцина. Вследствие этого возникает возможность отделения 5-алкилрезорцинов от других производных резорцина. Наши опыты показали, что таким способом можно разделить небольшое количество фенолов. При работе в препаративном масштабе целесообразнее делать это в колонке.

Целью настоящей работы было лрепаративное разделение изомерзых резорцинов способом, в основе которого лежат принципы распреде-

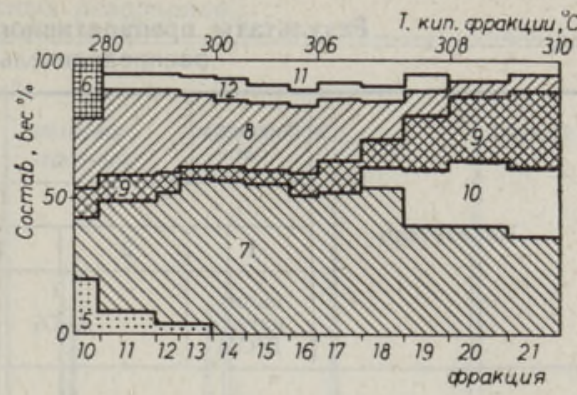

Рис. 1. Разделение фенолов, выделенных из подсмольной воды при ректифнкации.

Фенолы: 5 - резорцин, 6 - 2-метилрезорцин, 7 - 5-метилрезорцин, 8 - 4-метилре. зорцин, $9-5$-этилрезорцин, $10-12-$ неидентифицированные комионенты.

лительной хроматографии: вещество промывалось через колонку, заполненную адсорбентом и адсорбированным на нем неподвижным полярным растворителем, а для промывки использовался другой, менее полярный растворитель. Компоненты смеси распределялись между этими двумя растворителями. Таким способом можно разделить фенолы в зависимости от количества их гидроксильных групп и положения боковых цепей относительно этих групп.

В качестве исходного сырья была использована фракция фенолов с прєделами кипения $270 \ldots 310^{\circ} \mathrm{C}$, полученная при дистилляции суммарных фенолов подсмольной воды, выпускаемой сланцеперерабатывающим комбинатом им. В. И. Ленина.

Для выяснения оптимальных условий разделения использовались колонки разных размеров и с различным количеством адсорбента. В качестве адсорбента применялись окись алюминия и силикагель. Полярным растворителем служил бутилацетат, другой растворитель - дихлорэтан с разным количеством бутилацетата.

В начале цикла разделения хроматографическая колонка заполнялась бутилацетатом. Фенолы, растворенные в бутилацетате, подавались в верхнюю часть колонки и промывались последовательно вторым растворителем и бутилацетатом. Поэтому после вымывания последней части фенолов колонка оставалась заполненной бутилацетатом и была готова к следующему циклу разделения.

Данные, характеризующие цикл разделения, представлены в таблице.

Основным компонентом разделения является 5-метилрезорцин. Из таблицы видно, что максимальная концентрация 5-метилрезорцина в некоторых фракциях составляет $87 \ldots 95 \%$. На основе данных каждого опыта составлены графики, показывающие содержание отдельных компонентов в получаемых фракциях. На этих графиках отделена так наз. оптимальная зона по содержанию 5-метилрезорцина (фракции с содержанием 5-метилрезорцина выше $70 \%$ ).

Концентрат 5-метилрезорцина содержит $82 \ldots 91 \%$ основного компонента, что составляет более $70 \%$ от его потенциального содержания в сырье.

Хорошие результаты получены при использовании в качестве сольвента чистого дихлорэтана или дихлорэтана с бутилацетатом в отношении $9: 1$. Недостаток этого-увеличение расхода растворителя и соответственно времени проведения опыта, так как в связи с малой полярностью дихлорэтана первые компоненты вымываются относительно долго.

3 ENSV TA Tolmet:sed $K=\mathrm{G}-41970$ 
Результаты препаративного разделения 5-метилрезорцина распределительной хроматографией



* Оптимальная зона - фракции с содержанием 5-метилрезорцина выше $70 \%$.



Рис. 2. Распределение фенолов: в цикле распределительной хроматографии и состав вымывающего растворителя.

Фенолы: 1 - фенол, 2 - крезолы, 5 - резорцин, 6 - 2-метилрезорцин, $7-5$-метилрезорцин, 8 4-метилрезорцин, $9-5$-этнлрезорцин, $3,4,10-13-$ неидентнфнцированные компоненты.

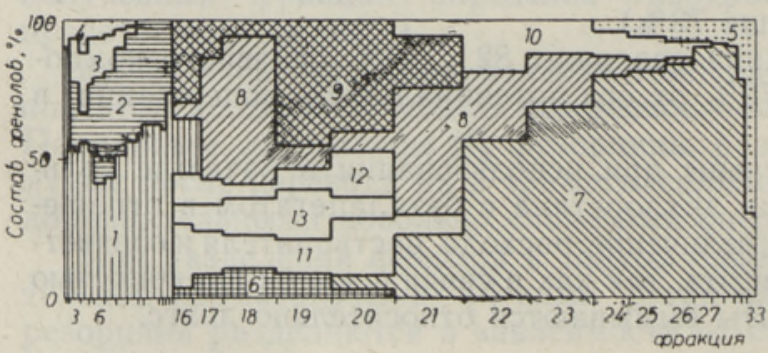

Полученные результаты показывают, что самое лучшее препаративное разделение происходит на окисн алюминия и на силикагеле ШСМ. Опти- 
мальный порядок растворителей: дихлорэтан и бутилацетат в соотношениях $9: 1,3: 1$ и чистый бутилацетат. В таких условиях проведен опыт с суммарными фенолами сланцевой подсмольной воды, результаты которого приведены в таблице (опыт 8), распределение компонентов в цикле разделения изображено на рис. 2 и газовые хроматограммы отдельных фракций приведены на рис. 3.

Основным компонентом сырого продукта является 5-метилрезорцин, концентрат которого (фракции $23 \ldots 31$; рис. 2) содержит 5-метилрезорцина 86 , резорцина - 6 и остальных компонентов - $8 \%$. После ректификации на колонке с разделительной способностью в 20 теоретических тарелок можно получить 5-метилрезорцин, чистотой не менее $95 \%$.

В промышленности широко используется адсорбционная и ионообменная хроматография для разделения веществ. Распределительная хроматография (распределение компонентов между подвижным и неподвижным растворителем, адсорбированным на носителе), по известным данным, ни в промышленном, ни в препаративном масштабе не была использована. В аналитической химии этим методом разделяют мнллиграммовые количества вещества, причем отношение между разделяемым веществом и адсорбентом составляет $1: 1000$. Причина такого соотношения в том, что носителем неподвижного растворителя обычно используется диатомит, который вследствие слабых адсорбционных свойств задерживает только незначительные количества растворителя. Для повышения адсорбционной емкости носителя в данной работе были использованы активные адсорбенты. Возможно, что и при разделении фенолов действуют адсорбционные явления, но это не имеет значения, так как опыты показали, что фенолы вымываются к концу цикла полностью.

При распределительной хроматографии и при экстракции используются взаимно нерастворимые растворители. Представленная пара растворителей (бутилацетат и дихлорэтан) образует одну фазу. Концентрации их в адсорбционном и в подвижном состоянии различны. Опытные данные показали, что другие растворители, находящиеся в элюотропическом ряду далеко друг от друга, не обеспечивают хорошего разделения. 
Результаты работы показывают, что изомеры резорцина можно разделить при помощи распределительной хроматографии. Безусловно, данный способ требует еще проверки на более крупной лабораторной установке.

\title{
ЛИТЕРА Т У Р А
}

1. Рятсеп А. Я., Бухте ева А. К., Добыча и переработка горючих сланцев, Л., вып. 16, 1967, с. 180.

2. Рятсеп А. Я., Р а удсепп Х. Т., Тр. Таллинск. политехн. ин-та, Сер. А, № 215, 183 (1964).

3. Лилле Ю. Э., Кундель Х. А., Биттер Л. А., Мурд А. Г., Пейнар У. Л., Авт. свид. № 199905; опубл. 29/VII 1967.

4. В ахесса ар В. А., К лесм ен т И. Р., Э й зен О. Г., Изв. АН ЭССР, Хим. Геол., 17, 3 (1968).

\author{
Ннститут химии \\ Академии наук Эстонской ССР \\ Поступила в редакцию \\ 3/VII 1969
}

I. KLESMENT, VIIVE VAHESSAAR, O. EISEN

\section{ISOMEERSETE RESORTSIINIDE LAHUTAMINE JAOTUSKROMATOGRAAFIA \\ ABIL}

Resortsiini isomeere on võimalik lahutada preparatiivse jaotuskromatograafia abil. Peamine komponent 5-metüülresortsiin väljub resortsiini derivaatidest viimasena. 5-metüülresortsiini kontsentraat sisaldab $82 \ldots 91 \%$ pōhiainet, mis moodustab $70 \%$ tema potentsiaalsest sisaldusest lähteaines.

I. KLESMENT, VIIVE VAHESSAAR, O. EISEN

\section{SEPARATION OF THE ISOMERS OF RESORCIN BY PARTITION CHROMATOGRAPHY}

The isomers of resorcin were separated by preparative partition chromatography. The main compound, 5-methylresorcin, was eluated from the column last. Its concentrate contains $82 \ldots 91$ per cent of 5 -methylresorcin, which makes up 70 per cent of its potential content in the mixture. 